\title{
Cardiac Stem Cell-based Regenerative Therapy for the Ischemic Injured Heart - a Short Update 2017
}

\author{
Mariann Gyöngyösi, Dominika Lukovic, Katrin Zlabinger, Ljubica Mandic, Johannes Winkler, \\ Alfred Gugerell
}

Department of Cardiology, Medical University of Vienna, Austria

\begin{abstract}
Cell therapy for the ischemic injured heart has been largely investigated in the last two decades, and most of the small cohort and randomized clinical studies, as well as meta-analyses led to the conclusion that cell-based human regenerative therapy is safe and effective in term of reducing adverse clinical outcomes and increasing left ventricular performance. Both the in vitro and in vivo rodent animal models of ischemic heart failure using bone marrow-derived mononuclear cells promised marvelous success in regeneration of the heart suffering from ischemic burden. However, in certain patient groups, stem cell studies failed to reach the primary endpoint, showing no effect of this regenerative therapy. This brief overview addresses the contradictory results between human cardiac regenerative studies and the very positive rodent experiments.
\end{abstract}

Keywords: stem cells, ischemic heart diseases, cardiac regeneration

\section{ARTICLE HISTORY}

Received: May 25, 2017

Accepted: June 2, 2017

\section{CORRESPONDENCE}

\section{Mariann Gyöngyösi}

Spitalgasse 23

1090 Wien, Austria

Tel: +4314040046140

E- mail: mariann.gyongyosi@

meduniwien.ac.at
Cell therapy for the ischemic injured heart has been investigated in the last two decades. Both the in vitro and in vivo rodent animal models of ischemic heart failure using bone marrow-derived mononuclear cells promised marvelous success in regeneration of the heart suffering from ischemic burden. Numerous positive findings of these experiments led to sustained enthusiasm for the clinical translation of cardiac regeneration. The triggers for cardiac cell-based therapies from the late 1990s included the differentiation of bone marrow mesenchymal stem cells into cardiomyocyte-like cells; enhanced angiogenesis when bone marrow-derived stem cells were injected into the infarcted left ventricular wall. World-wide well-known researchers reported that a certain fraction of bone marrow cells expressing c-kit marker, and also hematopoietic cells with $\mathrm{CD} 34+$ markers could give rise to new vessels and cardiomyocytes; the mobilization of bone marrow cells either spontaneously or using specific factors in the post-infarction period leads to the homing of these c-kit and $\mathrm{CD}_{34}+$ bone marrow cells in the myocardial infarction region, and these cells reduce infarct size and improve survival in animal models. Accordingly, over a decade, hundreds of clinical reports have emerged about the use of cell-based cardiovascular regenerative therapy for patients with ischemic heart disease with the hope of clinically relevant regeneration of the human ischemic injured myocardium by using bone marrow cells, but also peripheral progenitors, cardiospheres, or mesenchymal 


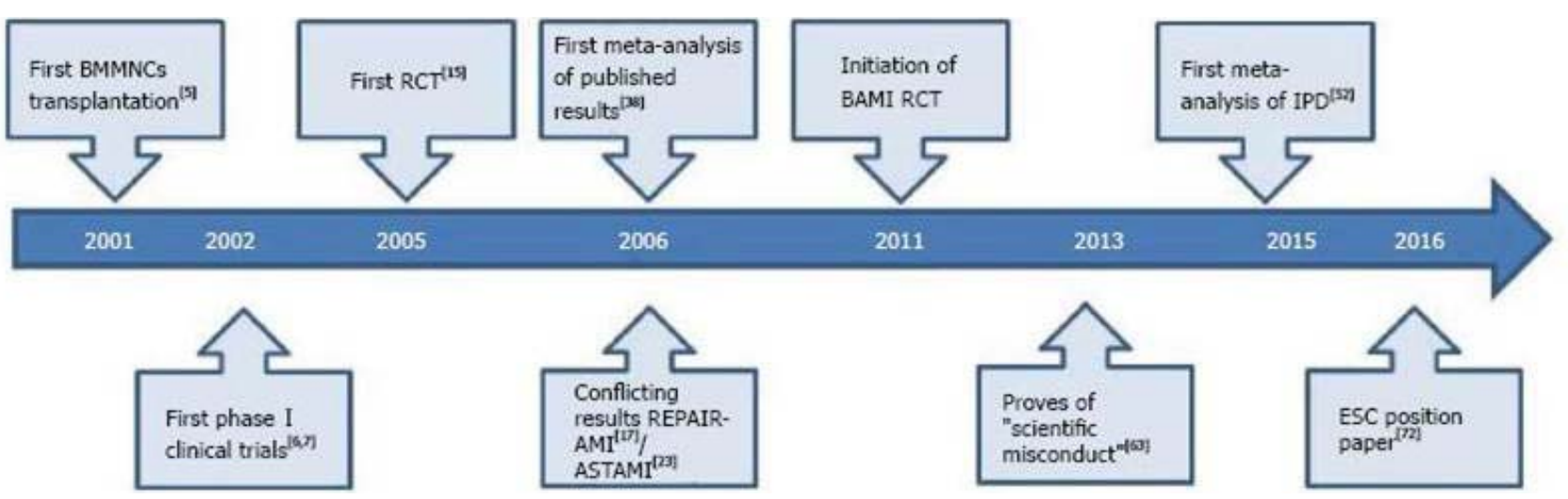

FIGURE 1. Fifteen years of bone marrow mononuclear cell therapy in acute myocardial infarction - time line chart.

From Micheu MM, Dorobantu M. Fifteen years of bone marrow mononuclear cell therapy in acute myocardial infarction. World J Stem Cells 2017; 9(4): 68-76. (reprinted with permission)

stem cells from diverse origins. Most of the small cohort and randomized clinical studies, as well as meta-analyses led to the conclusion that the cell-based human regenerative therapy is safe and effective in term of reducing adverse clinical outcomes and increasing left ventricular performance. However, after the first clinical study with no evidence of the beneficial effect of bone marrow-origin cell therapy in acute myocardial infarction, published in 2006, the number of trials and meta-analyses with neutral outcomes is increasing. ${ }^{1-6}$ In 2014, the DAMASCENE group has revealed several discrepancies in published clinical trials with regenerative medicine. ${ }^{7}$ In 2017 , it is likely that

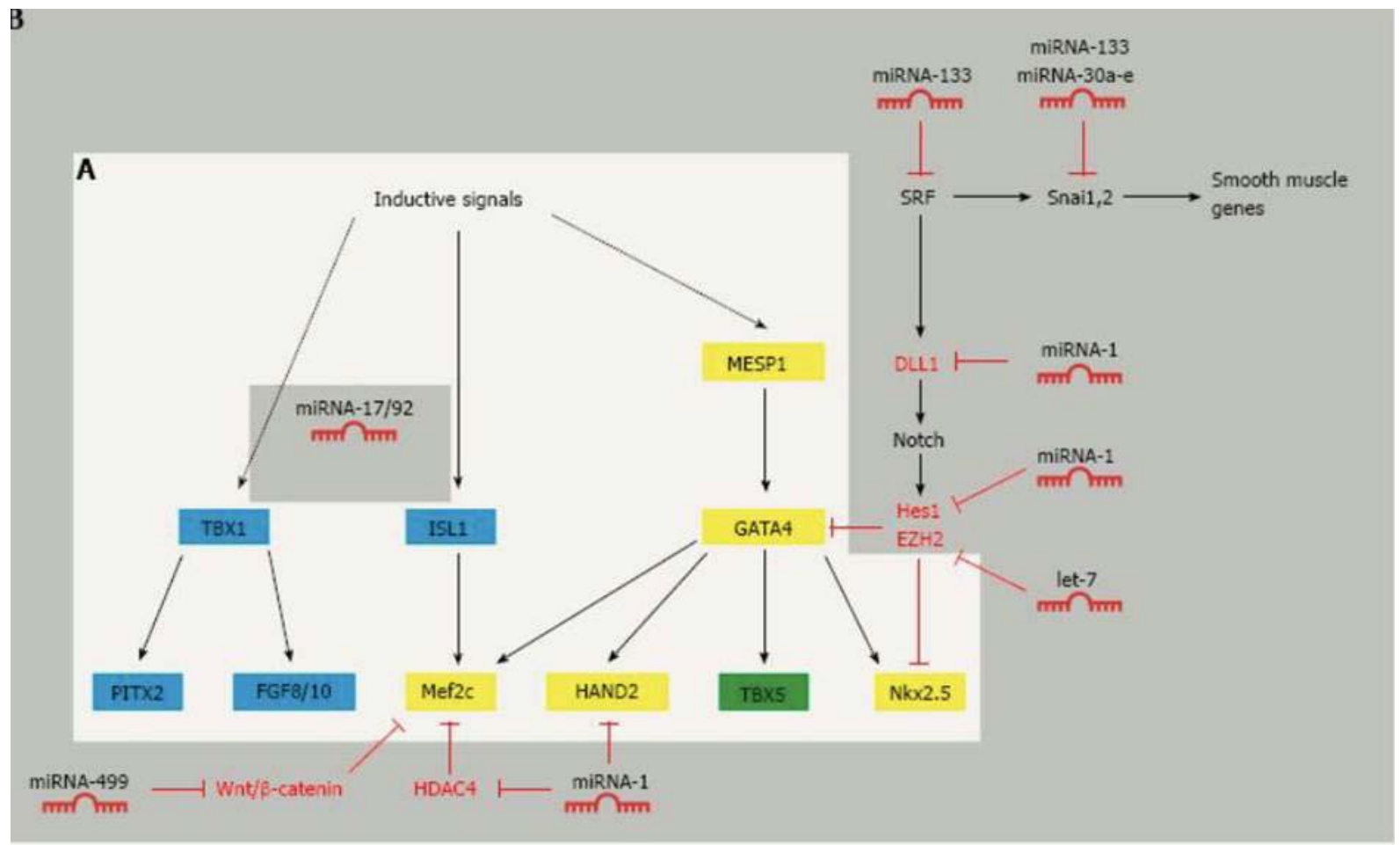

FIGURE 2. The complex web of transcription factors in cardiac specification and their regulation by microRNAs. A: Crosstalk between transcription factors involved in the formation of the first and second heart field (light grey box). MESP1, GATA4, Mef2c, HAND2 and Nkx2.5 are central transcription factors in the first and second heart field (yellow). TBX5 is only expressed in the first heart field (green). ISL1 and TBX1 are expressed in the second heart field (blue); B: MicroRNAmediated regulation of cardiac transcription factors during cardiomyocyte differentiation (dark grey box). 
one type of cell-based regenerative therapy, namely the intracoronary bone marrow-origin cell therapy is safe, but it offers no functional or clinical benefit (Figure 1).

There are other groups of patients who have chronic ischemic heart failure or refractory angina pectoris and are symptomatic in spite of maximal medical treatment and need cardiac regenerative therapy with anti-ischemic and anti-remodeling effect. The majority of these patients received cell or gene therapy, or manipulated autologous or allogeneic cells intramyocardially, percutaneously. Although the last updated Cochrane meta-analysis summarizing several small randomized study results reported a benefit of cell therapy in this patient population, the most recent randomized multicenter CHART-1 trial (intramyocardial injection of cardiopoietic cells for heart failure) failed to reach the primary endpoint, showing no effect of this regenerative therapy in this patient population. ${ }^{8}$

Why are the human cardiac regenerative studies contradictory to the very positive rodent experiments? There are endless explanations, such as comorbidities of the patients, "sick cell in sick patients" if autologous cells are used, or inappropriate cell dose and type, or the recipient milieu (e.g., inflammatory status or lack of cell homing signals).

According to the rising skepticism in the cardiac regeneration field, the question arises, whether cardiac cell-based therapy for heart disease should be continued in humans? Recognizing the scant evidence of efficacy of the first approaches of cardiac regeneration therapies, the second and third generations of cells and cell therapies are currently under way also in the clinic. Furthermore, refinement of the concepts of cell reprogramming continues, novel gene therapies or tissue engineering, or the local stimulation of endogenous remnant cardiac stem cells with secretomes, exosomes, or other cardiopoietic or immune-modulatory approaches are under testing. Additionally, the role of cell-realted, exosome-bound, cellfree circulating, or locally released oligonucleotids (e.g., non-coding RNAs) is under investigation in the cardiac regeneration processes (Figure 2).

Summarizing the experiences of the past, a position paper has recently been published with facts and clear guidelines for cardiac cell-based therapies. ${ }^{9}$ According to the continuous effort to improve clinical regenerative therapies, large clinical multicenter randomized studies are under way with novel concepts regarding the mechanism of action, such as the European Commission-supported SCIENCE (percutaneous intramyocardial delivery of allogeneous stem cell for treatment of heart failure) or the ReGenHeart (percutaneous intramyocardial gene therapy for refractory angina pectoris). We, in the Department of
Cardiology, Medical University of Vienna are participants in both of these trials, with the aim to achieve better quality of life of patients through treatment of therapy-resistant heart failure and angina pectoris, and to provide novel information regarding the biological mechanism of action.

\section{CONFLICT OF INTEREST}

None declared.

\section{REFERENCES}

1. Lunde K, Solheim S, Aakhus S, et al. Intracoronary injection of mononuclear bone marrow cells in acute myocardial infarction. N Engl J Med. 2006;355:1199-1209. doi: 10.1056/ NEJMoa055706.

2. Quyyumi AA, Vasquez A, Kereiakes DJ, et al. A Randomized, Double-Blind, Placebo-Controlled Clinical Trial of Intracoronary Administration of Autologous CD34+ Cells in Patients With Left Ventricular Dysfunction Post STEMI. Circ Res. 2017;120:324-331. doi: 10.1161/CIRCRESAHA.115.308165.

3. Wollert KC, Meyer GP, Müller-Ehmsen J, et al. Intracoronary autologous bone marrow cell transfer after myocardial infarction: the BOOST-2 randomised placebo-controlled clinical trial. Eur Heart J. 2017. doi: 10.1093/eurheartj/ehx188. [Epub ahead of print]

4. Gyöngyösi $M$, Wojakowski W, Lemarchand $P$, et al. MetaAnalysis of Cell-based CaRdiac stUdiEs (ACCRUE) in patients with acute myocardial infarction based on individual patient data. Circ Res. 2015;116:1346-1360. doi: 10.1161/ CIRCRESAHA.116.304346.

5. Fisher SA, Doree C, Mathur A, Martin-Rendon E. Metaanalysis of cell therapy trials for patients with heart failure. Circ Res. 2015;116:1361-1377. doi: https://doi.org/10.1161/ CIRCRESAHA.116.304386.

6. Fisher SA, Zhang H, Doree C, Mathur A, Martin-Rendon E. Stem cell treatment for acute myocardial infarction. Cochrane Database Syst Rev. 2015;9:CD006536. doi: 10.1002/14651858. CDo06536.pub4.

7. Nowbar AN, Mielewczik M, Karavassilis M, et al. DAMASCENE writing group. Discrepancies in autologous bone marrow stem cell trials and enhancement of ejection fraction (DAMASCENE): weighted regression and meta-analysis. BMJ. 2014;348:g2688. doi: 10.1136/bmj.g2688.

8. Bartunek J, Terzic A, Davison BA, et al. Cardiopoietic cell therapy for advanced ischaemic heart failure: results at 39 weeks of the prospective, randomized, double blind, shamcontrolled CHART-1 clinical trial. Eur Heart J. 2017;38:648660. doi: https://doi.org/10.1093/eurheartj/ehw543.

9. Fernández-Avilés F, Sanz-Ruiz R, Climent AM, et al. Global position paper on cardiovascular regenerative medicine: Scientific statement of the transnational alliance for regenerative therapies in cardiovascular syndromes (TACTICS) international group for the comprehensive cardiovascular application of regenerative medicinal products. Eur Heart J. 2017. doi: 10.1093/eurheartj/ehx248. [Epub ahead of print] 